\title{
Extending capacity utilisation measures from railway network links to nodes
}

\author{
J. Armstrong \& J. Preston \\ on behalf of the OCCASION consortium \\ Transportation Research Group, Faculty of Engineering and the \\ Environment, University of Southampton, UK
}

\begin{abstract}
Railway capacity is increasingly scarce and valuable, but is also inherently difficult to define and measure. To develop a full understanding of the capacity situation in a railway network or any of its constituent nodes and links, measures are needed of both (i) capacity provision, in terms of e.g. trains/passengers/TEU per hour, and (ii) capacity utilisation or consumption, in terms of the percentage of potential capacity that a given timetable utilises. This is because a given level of capacity provision can be timetabled in different ways, with varying levels of capacity utilisation, and, conversely, for a given level of capacity utilisation, significantly different levels of capacity can be provided, depending upon the train service pattern and mix. On busy networks, the typical objective is to provide as much capacity as possible for a given level of capacity utilisation, or, alternatively, to minimise the level of capacity utilisation for a given level of capacity, thus maximising capacity while making efficient use of the network and maintaining service reliability, which deteriorates as capacity utilisation increases. Recognised Capacity Utilisation measures are available for network links (e.g. the UIC 406 method, and the UK-specific CUI measure), but not for the junctions and stations forming the nodes which typically constrain network capacity. The benefits of extending the methodologies to nodes are widely recognised, particularly in the context of ever-increasing capacity demands. This paper describes the extension of existing capacity utilisation measures to enable their application to both junction and station nodes, and the development of algorithms and programs to enable their rapid calculation. Examples of simple and complex nodes are presented, and needs for further work are identified.
\end{abstract}

Keywords: railway, capacity, capacity utilisation, nodes, junctions, stations. 


\section{Introduction}

Following several decades during which surplus railway lines and routes were steadily removed from national networks, increasing levels of passenger and freight demand have resulted in railway capacity being a scarce and valuable commodity. It is also an elusive measure, and it is difficult, if not impossible, to define a specific capacity value for any given track, route or network, and the achievable capacity will depend on how it is used. A range of capacity values may be provided for a given level of capacity utilisation; similarly, different levels of capacity utilisation may be achieved for a given level of capacity provision, depending upon how the capacity is provided.

This element of railway operations planning is particularly topical in Britain, following the publication of the McNulty Report [1] and the subsequent Government Command Paper [2], Reforming our Railways: Putting the Customer First, both of which emphasise the need to make the best possible use of existing (and additional) capacity.

Where capacity is scarce, the objective is usually to maximise the capacity provided, while avoiding levels of capacity utilisation that preclude a stable, reliable quality of service. To deliver this, measures of capacity provided and capacity utilisation are needed for all parts of the route or network in question, i.e. at nodes (junctions and stations) as well as the links connecting them. Wellknown capacity utilisation measures exist for links, but not generally for nodes.

This paper describes the initial development of generic capacity utilisation measures for both junctions and stations, undertaken as part of the OCCASION (Optimising Capacity Constraints: A Simulation Integrated with Optimisation of Nodes) project for use in the development of generalised measures of network capacity utilisation. Following this introduction, Section 2 provides some background, including descriptions of measures of capacity and capacity utilisation, and limitations of the current measures. Section 3 then describes the extension of the Capacity Utilisation Index (CUI) measure of capacity utilisation, to enable the assessment of junction and station nodes. Some preliminary results are presented, and, finally, Section 4 presents some conclusions.

\section{Background: railway capacity and its utilisation}

According to UIC [3], "capacity as such does not exist [and] railway infrastructure capacity depends on the way it is utilised." Achievable capacity thus depends not only upon the infrastructure characteristics, but also upon the performance characteristics and mix of trains on the route, the timetable used, and the punctuality to be achieved by the trains.

Two key objectives in railway capacity provision are: (i) making the best use of the capacity that is potentially available, i.e. seeking to maximise the number (and, as appropriate, length) of trains that can be operated, subject to constraints imposed by service mix, stopping patterns, etc., and (ii) the related issue of maintaining service quality by limiting the number of trains operated, to ensure that reliability is maintained at the required level. Capacity Utilisation 
assessments relate to both these objectives, in that the greater the number of trains being run for a given level of Capacity Utilisation, the greater the level of capacity being provided; and the greater the level of Capacity Utilisation, the less likely the service is to be reliable, with quality levels deteriorating rapidly for Capacity Utilisation levels in excess of $60 \%-70 \%$ over extended periods, and in excess of $75 \%-85 \%$ over shorter, peak periods [3].

\subsection{Current methods and their limitations}

Capacity utilisation can be taken into consideration and/or measured in various ways, from timetable planning in accordance with the relevant rules, to the use of detailed operational simulation to assess the performance of a proposed timetable and infrastructure combination. Two of the best-known, capacity utilisationspecific, analytic approaches are the international UIC 406 method (UIC, 2004) and, in Britain, the Capacity Utilisation Index (CUI) method, as described by Gibson et al. [4]. The two methods are similar in approach, both employing the technique of 'timetable compression', but vary in the level of detail at which they are applied, since the UIC 406 method is applied at the signal block level, whereas the CUI method is applied to longer route sections, and does not consider individual block sections. The CUI method is the more relevant to the British operating context, since it is based upon the timetable and capacity planning process employed, as set out in the Timetable Planning Rules (formerly known as the Rules of the Plan) produced by Network Rail, the owner and operator of most of Britain's heavy rail infrastructure. The CUI approach is summarised in Figure 1, reproduced from Gibson et al. [4].

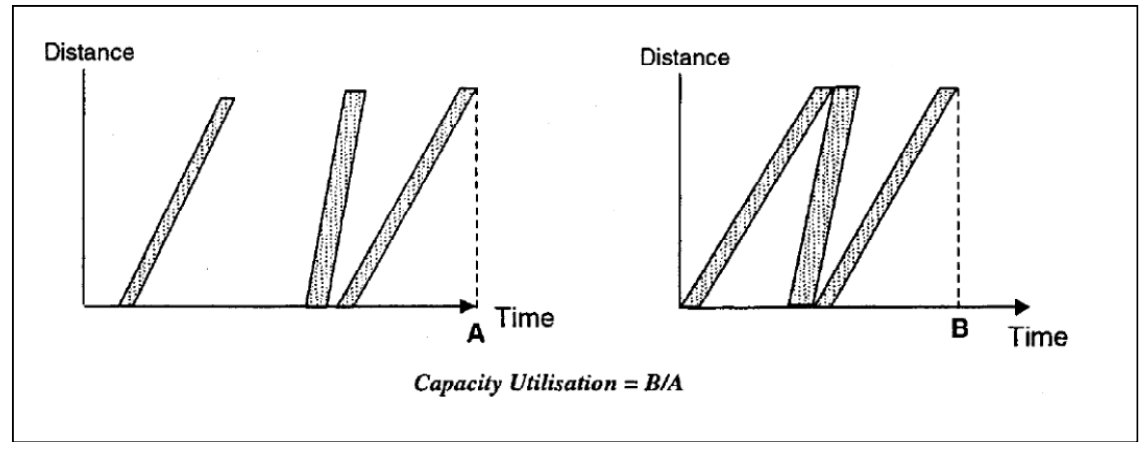

Figure 1: Definition of capacity utilisation [4].

A limitation of the UIC 406 and CUI methods is that their application beyond simple track sections between nodes is not straightforward: it is recommended in [3] that, for the application of the UIC 406 compression mechanism, "ideally, the line section used for compression should be reduced to the line section between two neighbouring stations (without overtaking or crossing possibilities)", while the CUI methodology is also currently limited to such 'plain line' sections between nodes. While the UIC406 method can, in principle, be applied to 
junctions and stations, the recommended levels of maximum utilisation for plain line sections are not valid for platform tracks and junctions. This limitation is recognised by UIC; as noted in its 2009 list of projects [5] in reference to the UIC Leaflet 406 Revision:

The current UIC Leaflet 406 provides generally-valid guidelines and methodology to assess the capacity on the lines whilst the particularities of nodes (stations and junctions) are only briefly mentioned.

It recommended that

the capacity assessment on lines, as described currently in the leaflet, should be revised. The capacity assessment in nodes needs to be introduced and analysed with the same depth than the capacity on lines.

The authors are not aware of the current status of this project, or that any findings have emerged.

The situation is similar in respect of the CUI methodology, and it is recognised by industry practitioners that, for example, it is not particularly useful to have a methodology which indicates that the approaches to a station are working at an acceptable level of capacity utilisation, when the methodology provides no means of assessing the levels of capacity utilisation within the station itself, where the capacity constraints are likely to be located. There is thus a need and an opportunity to extend the CUI methodology in a similar direction to that proposed by UIC for Leaflet 406. Although the underlying issues may be complex, there is potential for significant benefits arising from the development of an outwardly simple, generic methodology and tool for the assessment of nodal capacity utilisation. Preliminary work conducted on this task is described by Armstrong et al. [6], and summarised below. Similar work, based on the UIC 406 approach, has been undertaken by others: while Lindner [7] expresses scepticism about the application of timetable compression to the assessment of railway nodes, the approach has been applied successfully by Landex [8] and by Libardo et al. [9].

\section{Extension of existing CUI methodology}

This section summarises the extension of the CUI methodology to simple junctions and stations, as described in [6], and then describes the further application of these extensions to a more complex example.

\subsection{Simple junction and station node examples}

Junctions vary in size and complexity from the simplest turnout to situations where multiple, multi-track routes converge, cross and diverge, examples of the latter in Britain including Woking Junction, Proof House Junction (on the eastern approach to Birmingham New Street station), and Reading West Junction. 
The fundamental distinction between a simple, through station and a section of plain line is that some trains, at least, are timetabled to stop at the station, introducing dwell times, where the trains are scheduled to be stationary. As station layout complexity increases, and individual approach tracks serve multiple platforms, or single platforms are connected to multiple departure tracks, stations resemble junctions, again with the exception that at least some trains are scheduled to stop. A further element of complexity is introduced where trains stop, and then change direction within a station, either at a bay platform, where there is no alternative, or at a through platform, where a train arrives in one direction, but then departs in another.

\subsubsection{Pirbright Junction}

The initial development of this methodology is based on an assessment of Pirbright Junction, between Woking and Basingstoke on the South West Main Line (SWML) from London to the south-west of England, where the line to Aldershot and Alton joins the SWML. In the Up (London-bound) direction, the junction comprises a simple set of trailing points, with a corresponding set of facing points in the Down direction, as shown schematically in Figure 2. The following analysis is based on the node forming the Up junction.

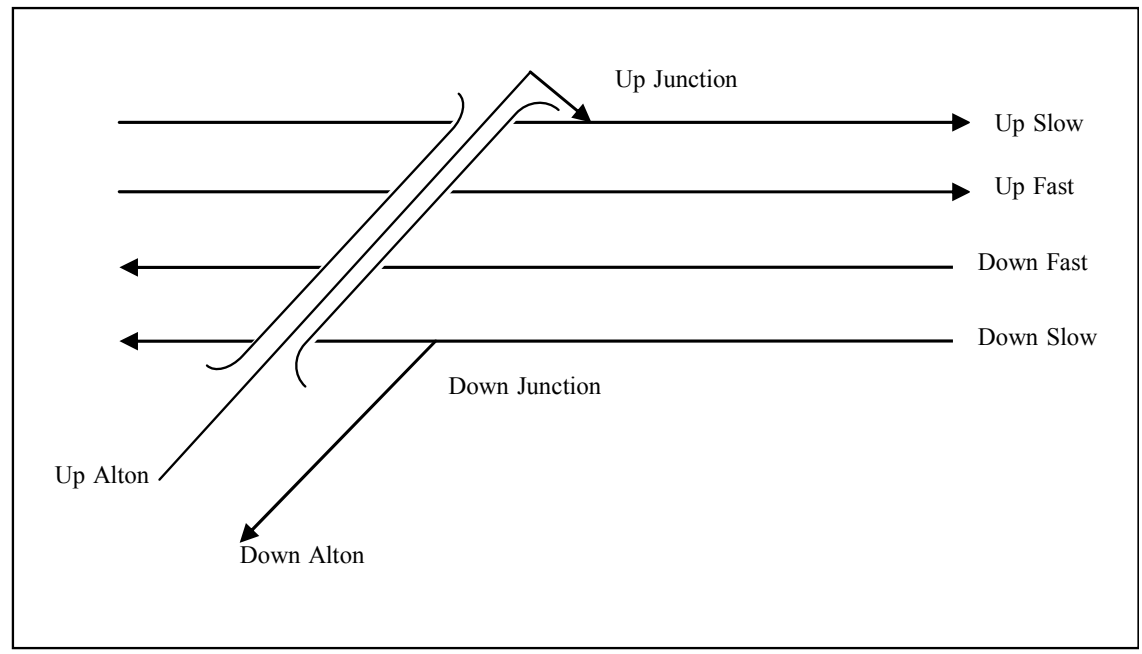

Figure 2: Pirbright Junction.

According to the Timetable Planning Rules [10], the minimum junction margin for Pirbright Junction is the standard for the route, of three minutes between all train movements, equivalent to a minimum headway of three minutes on a section of plain line. The weekday timetable graph for the Up Slow line between 08:00 and 09:00, including trains joining from the Up Alton line, is shown in Figure 3, with Pirbright Junction highlighted (the graph is based on the December 2007 timetable for the line). 


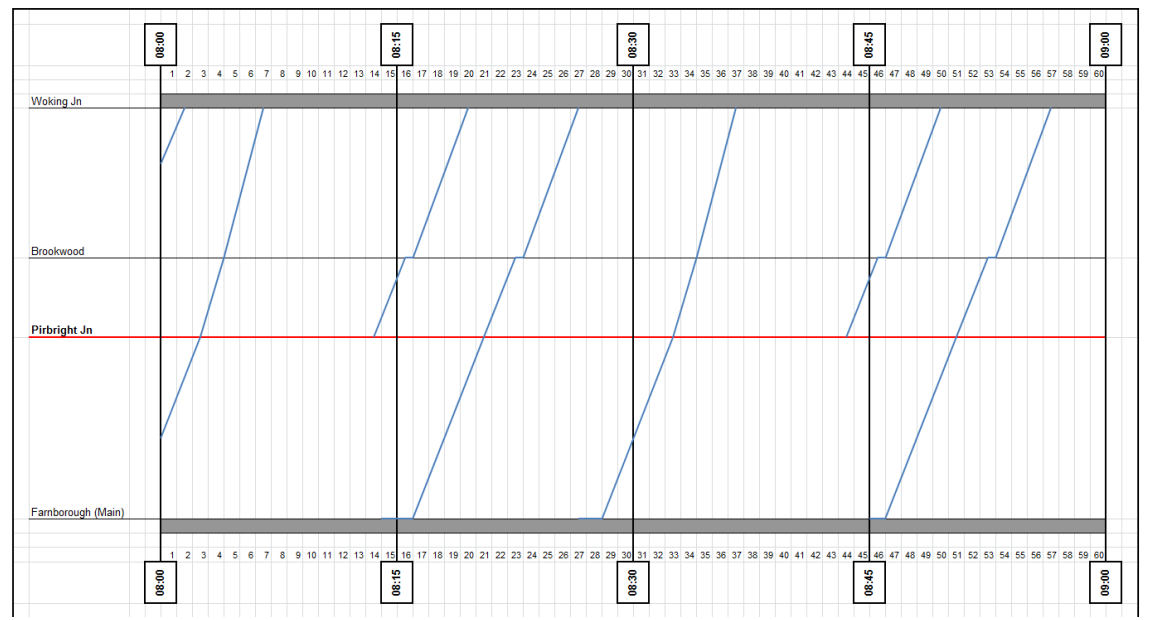

Figure 3: Uncompressed timetable graph for Pirbright Junction.

The equivalent compressed graph is shown in Figure 4, with compression applied to trains at Pirbright Junction only, ignoring effects on the adjacent line sections (note the diminishing headway between the third and fourth trains shown, between Pirbright Junction and Woking Junction). By reducing the interval between successive movements through Pirbright Junction to three minutes, the time between the first and last trains is 18 minutes (including the margin after the last train), representing a CUI of $18 / 51=35.3 \%$ (51 minutes $=$ 48 minutes (the time between the first and last trains) plus 3 minutes margin, giving the CUI for the interval between the first and last trains; the CUI for the full hour between 08:00 and 09:00 is correspondingly lower, at 18/60=30\%).

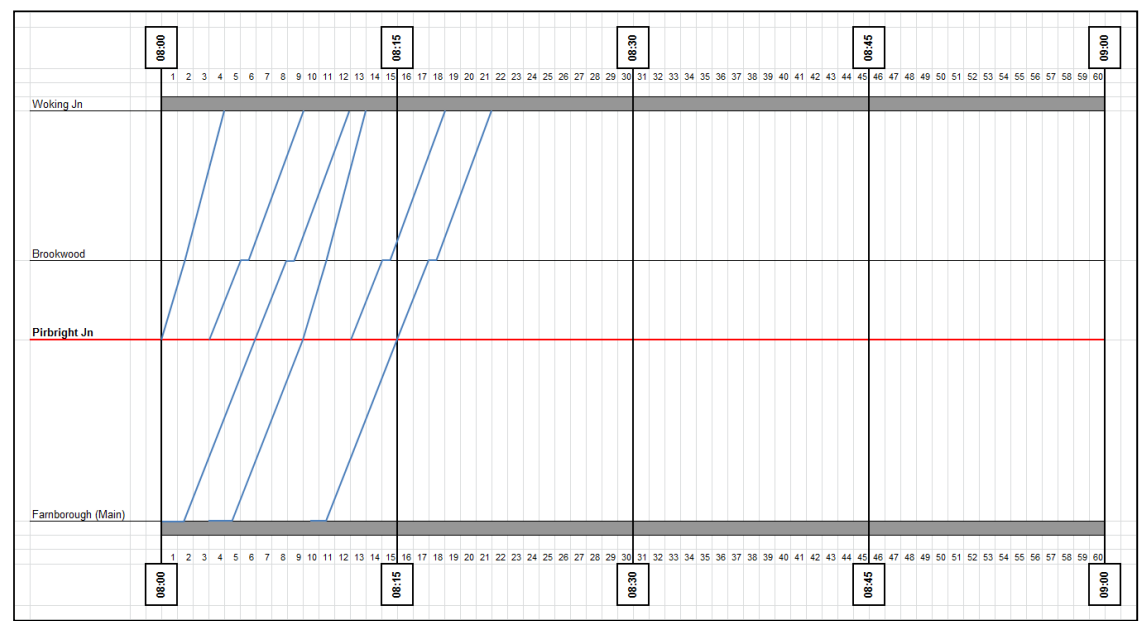

Figure 4: Compressed timetable graph for Pirbright Junction. 


\subsubsection{Southampton airport (Parkway) station}

The initial development of the station element of the expanded CUI methodology was based on an assessment of Southampton Airport (Parkway) station, a busy commuter station located on the SWML between Southampton Central and Eastleigh stations, served by a mixture of local services and longer-distance trains operating between London and the south coast, and across the wider 'cross country' network. The station is shown schematically in Figure 5. The following analysis is based on trains travelling in the Up direction (i.e. towards Eastleigh and London), but again could easily be applied to the Down direction.

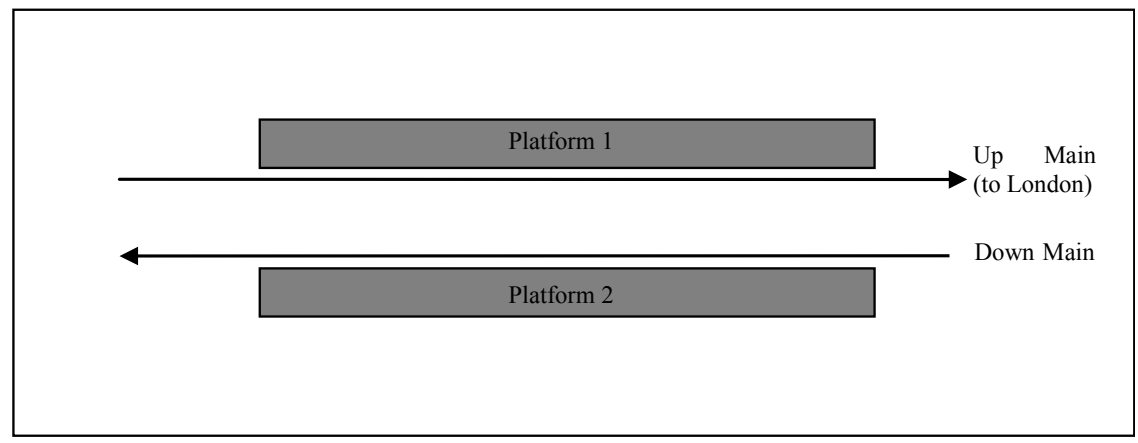

Figure 5: Southampton Airport (Parkway) station.

The Timetable Planning Rules [10] do not specify a minimum platform reoccupation time for the station, but do specify minimum fast and slow headway values for different sections of the SWML: for the section of the route in question (Eastleigh - Redbridge), the slow value of $2 \frac{1}{2}$ minutes is applicable. The weekday timetable graph for the Up Main line between 08:00 and 09:00 is shown in Figure 8, with Southampton Airport (Parkway) highlighted (again, this is based on the December 2007 timetable for the line).

The December 2007 weekday timetable graph for the Up Main line between 08:00 and 09:00 is shown in Figure 6, with Southampton Airport (Parkway) highlighted. The time between the first and last trains at Southampton Airport (Parkway) is $57-6 \frac{1}{2}=501 / 2$ minutes, to which the headway value of $2 \frac{1}{2}$ minutes is added for the CUI calculation, giving an overall time value of 53 minutes.

The equivalent compressed graph is shown in Figure 7, with compression applied to trains at Southampton Airport (Parkway) only, again excluding the headway before the first train, and ignoring any effects on the adjacent line sections (again, note the reduction of the headway between the third and fourth trains at St Denys). It can be seen that, by reducing the interval between the departure and arrival of successive services at Southampton Airport (Parkway) station to $2 \frac{1}{2}$ minutes, the time required between the arrival of the first and the departure of the last trains is 20 minutes $\left(=171 / 2\right.$ minutes $+2 \frac{1}{2}$ minutes, including the headway after the last train), representing a CUI of $20 / 53=37.7 \%$. As in the previous example, the CUI for the full hour would be slightly lower. 


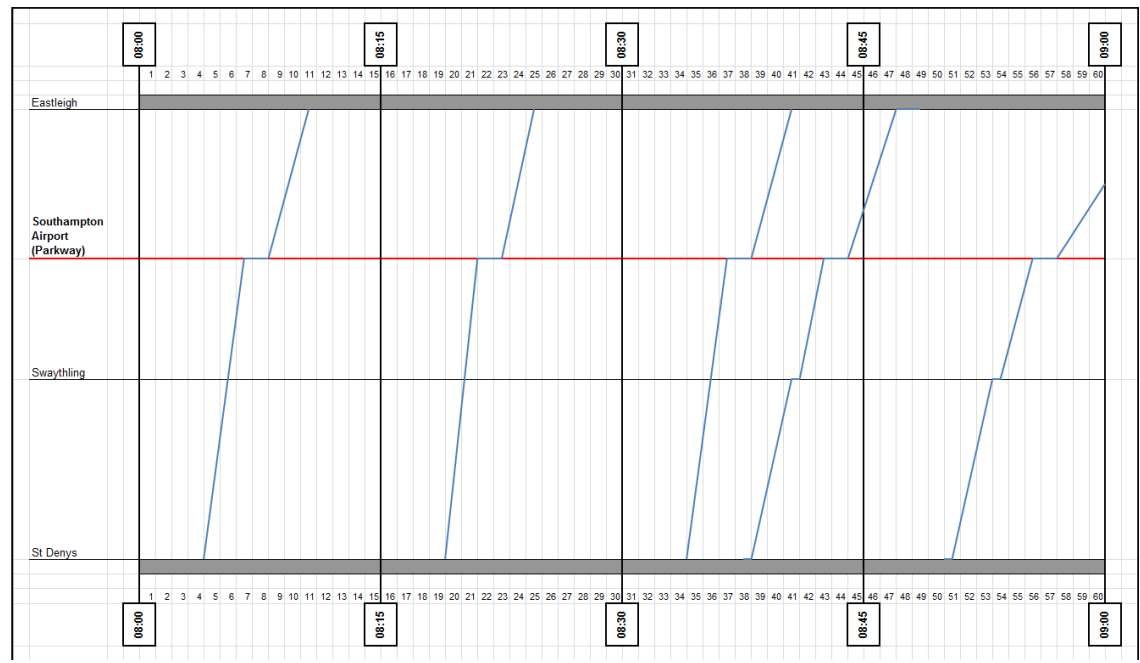

Figure 6: Uncompressed timetable graph for Southampton Airport (Parkway).

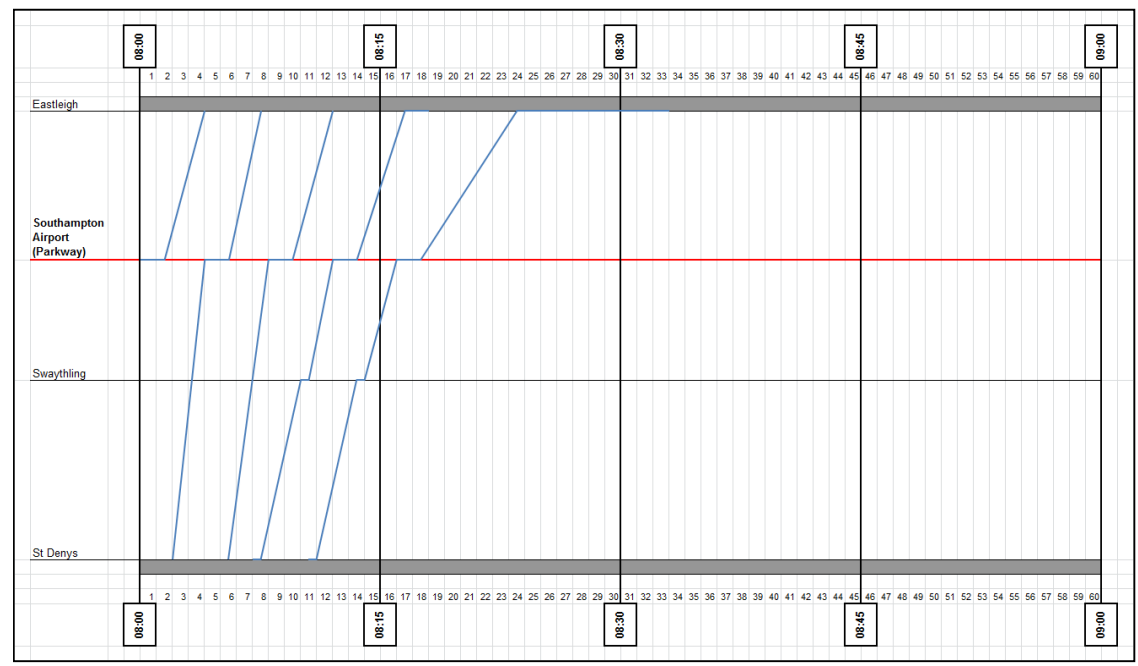

Figure 7: Compressed timetable graph for Southampton Airport (Parkway).

The examples shown represents the simplest node layouts possible, and thus provide the basic 'building blocks' for the assessment of more complex examples, which can be treated as a collection of simple nodes, for which individual and overall average values are calculated, enabling the identification of heavily- and lightly-used elements of the overall node layouts. 
In reality, operating five or six successive trains through a node at minimum margins is likely to affect service reliability and quality, and the Timetable Planning Rules require the provision of additional margins in such cases.

\subsection{A more complex example}

The principles described above were applied to a more complex example for the OCCASION project. Various case study options were examined, and the section of the East Coast Main Line (ECML) between Huntingdon and Grantham was chosen. This route section includes Peterborough, thus enabling the extension of the modelling process to a reasonably complex station and junctions, but also an example that is not at such a large scale as to overcomplicate the model development and results.

\subsubsection{Peterborough station and adjacent nodes}

The case study area is shown in outline form in Figure 8, which shows the stations and junctions along the route, and the varying number of tracks. The Peterborough station area is shown in more detail in Figure 9.

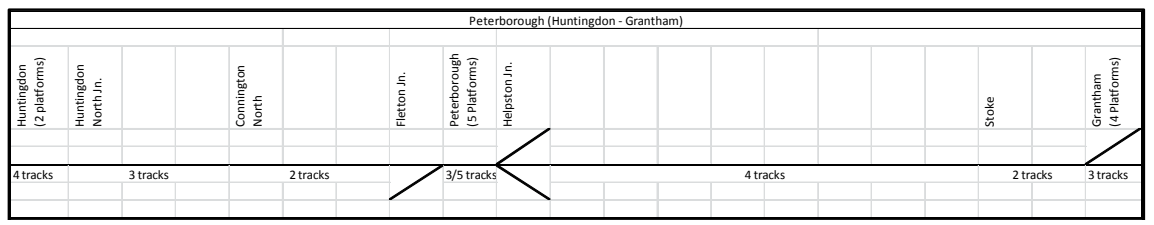

Figure 8: $\quad$ Line diagram of Huntingdon - Grantham case study area.

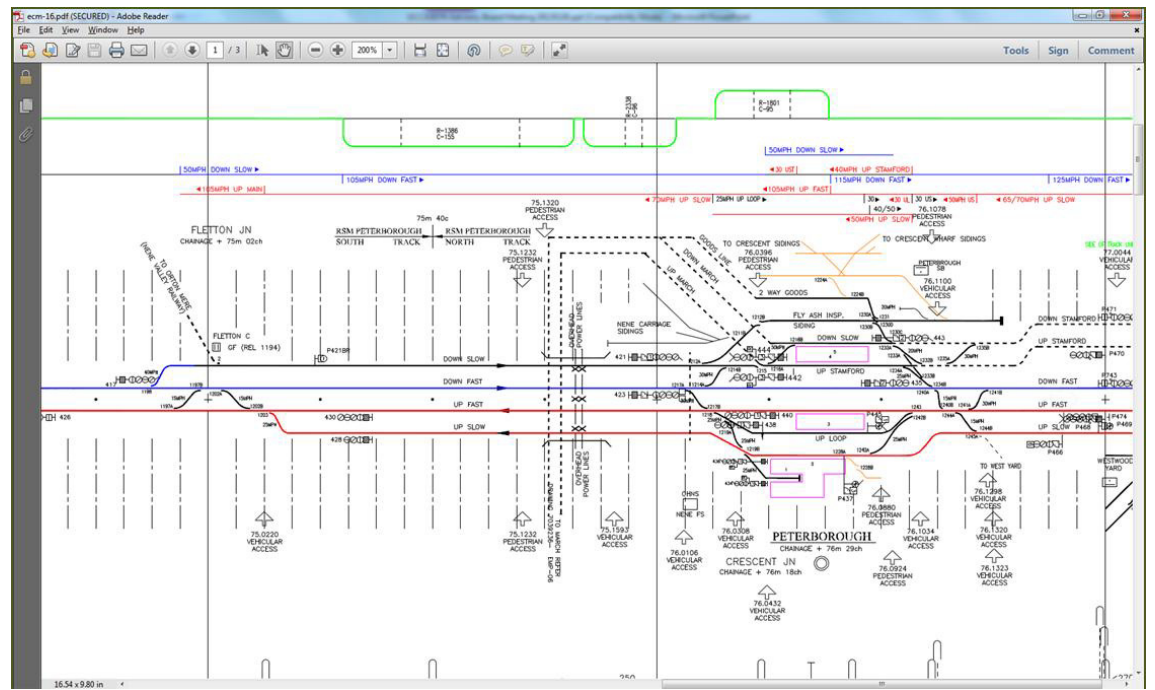

Figure 9: $\quad$ Peterborough station area track layout. 


\subsubsection{Timetable data sources and import}

Timetable data for the ECML were provided in CIF (Common Interface File) format by Network Rail (note: current, network-wide CIF data are now freely available to download from the Association of Train Operating Companies' (ATOC's) website). A Perl script was written to extract the data records for trains passing through the case study area. The CIF data specifies arrival, departure and passing times at Timing Point Locations (TIPLOCs) representing stations, junctions, passing/freight loops and some signals on the network, including platform numbers and some information on the arrival and departure tracks used by trains.

\subsubsection{Subsequent data processing}

To determine the detailed routeings of individual trains through the network, a node-link model of the case study area was developed, representing individual switches, crossings and platforms, and their intermediate links. The Perl script was extended to identify the detailed routes taken through the model, and to calculate the times at which trains pass all intermediate nodes (simple distancebased interpolation of times is used, which is an adequate approximation for timetable compression purposes, but more detailed and accurate timing data could be imported from RailSys, for example).

When the intermediate nodal timings have been determined for each train, the timing data are aggregated by node, sorted into sequence and compressed to minimum headway values to determine CUI values for each node in the network. A value of four minutes throughout has been assumed for the work to date, but this will be refined to take account of local variations and the effects of conflicting moves between trains to and from adjacent platforms at Peterborough, for example.

The situation is similar, but somewhat more complicated, for links, particularly in the case of bi-directional working, where the data have to be aggregated for both directions of travel, and then sorted in order of link entry or exit times. The shortest intervals between successive trains on each link are then compressed to the minimum headway value, to obtain a CUI value for each link.

For both nodes and links, two CUI values are calculated: one for occupation utilisation as a percentage of the overall time period under consideration, and one for the time between the first and last trains to use the node or link during that period, omitting any preceding or following 'white space' in the timetable. Depending upon the number and timings of trains in operation, these values can vary considerably; the former gives an indication of the overall level of utilisation, while the latter illustrates levels of maximum utilisation, and thus the likely implications for service quality and reliability. Average CUI values for both nodes and links can easily be calculated, although this requires careful consideration and a degree of caution, since, depending upon the calculation approach adopted, some nodes or links may have very low or high utilisation values (up to $100 \%$, for example, if the latter approach is adopted and only a single train uses a node or link during the time period in question), thus skewing the overall results. 


\subsubsection{Results}

The results, calculated for the period between 07:00 and 09:00 on a weekday morning, are too extensive to present in detail within the page limit of this paper, but, in general terms, a similar range of values was obtained for both links and nodes, from $0 \%$ where network elements were unused (e.g. in the case of emergency crossovers, over which movements are not normally scheduled) to $91 \%$ for nodes and $51 \%$ for links as a proportion of the overall two-hour period, while both had utilisation values of $100 \%$ between the first and last trains, as noted above. Average values were $25 \%$ and $23 \%$ for nodes and links respectively for the overall period, and $32 \%$ and $62 \%$ for the periods between first and last trains. The results obtained are broadly consistent with those produced by another element of the OCCASION project, in which job shop optimisation techniques are used to insert additional trains into the timetable [11].

\subsection{Further work}

As noted above, further work is required to refine the process outlined, including the handling of headway and margin variations, and the graphical representation of results. In order to produce definitive results in terms of timetable quality and reliability (as opposed to comparisons between different scenarios), it will be necessary to investigate and determine suitable $\mathrm{CU}$ limits for nodes, equivalent to those available for links. Possible means of developing these include the analysis of historic performance data, and the use of simulation.

In addition to the technical issues described above, some work is required to standardise and document the CUI approach and process, to produce equivalent guidance to that set out for UIC Leaflet 406 [3], for example.

\section{Conclusions}

In conclusion, railway capacity is increasingly scarce, and means are being sought to make better use of the potential capacity that is already available. To achieve this goal, in the absence of standard capacity measures and definitions, standard measures and means are required for the calculation of the capacity utilisation of nodes, equivalent to those available for network links.

This paper describes the initial development of such measures and methods, and their application to a comparatively complex case study. The method adopted is based on the UK-specific CUI approach, although the techniques developed are more generally applicable.

Various requirements and opportunities have been identified to extend and further develop the approach, and it has already attracted interest from Network Rail, the owner and operator of most of Britain's heavy rail infrastructure.

\section{References}

[1] McNulty, R. (ed.), Realising the Potential of GB Rail: Final Independent Report of the Rail Value for Money Study: Detailed Report. Department for Transport \& Office of Rail Regulation: London, 2011. 
[2] Department for Transport, Reforming our Railways: Putting the Customer First. The Stationery Office: London, 2012.

[3] UIC (Union Internationale Des Chemins De Fer), Leaflet 406: Capacity. UIC, Paris, 2004.

[4] Gibson, S., Cooper, G., Ball, B., "Developments in Transport Policy: The Evolution of Capacity Charges on the UK Rail Network", Journal of Transport Economics and Policy, Vol. 36, Part 2, pp. 341-354, May 2002.

[5] UIC, List of projects [online], Union Internationale Des Chemins De Fer (UIC), UIC, Paris, 2009. Available from http://www.uic.org/ baseinfo/projet/projet.php?id=208 [Accessed 2 November 2010].

[6] Armstrong, J., Blainey, S. Preston, J., Hood, I., Developing a CUI-based Approach to Network Capacity Assessment. Proceedings of the 4th International Seminar on Railway Operations Modelling and Analysis: Rome, 2011.

[7] Lindner, T., Applicability of the analytical compression method for evaluating node capacity. Proceedings of the 4th International Seminar on Railway Operations Modelling and Analysis: Rome, 2011.

[8] Landex, A., Station Capacity. Proceedings of the 4th International Seminar on Railway Operations Modelling and Analysis: Rome, 2011.

[9] Libardo, A., Pellegrini, P., Salerno, G., Capacity in Railway Junctions and Optimal Route Management. Proceedings of the 4th International Seminar on Railway Operations Modelling and Analysis: Rome, 2011.

[10] Network Rail, Timetable Planning Rules Engineering Access Statement [online], Network Rail (2010). Available from http://www.networkrail.co.uk/browse \%20documents/Rules\%200f\%20The \%20Route/roprhome.pdf?a=11Apr [Accessed 24 April 2012].

[11] Paraskevopoulos, D.C, Bektas, T., Potts, C.N., Armstrong, J. and Preston, J. Increasing Nodal Capacity by Redesigning the Train Timetable: A case study on the UK's railway. Mimeo, University of Southampton. April 2012. 